\title{
Factors Associated with Consuming Junk Food among Saudi Adults in Jeddah City
}

Najlaa Mandoura ${ }^{1}$, Rajaa Al-Raddadi ${ }^{2}$, Ola Abdulrashid ${ }^{1}$, Hassan B. Usman ${ }^{1}$, Sulaiman M. Kassar $^{3}$, Abdul Rehman Adel Hawari ${ }^{3}$, Jana M. Jahhaf ${ }^{3}$

1. Epidemiology and Public Health, Directorate of Health Affairs for Public Health Division, Jeddah, SAU

2. Consultant Preventive Medicine, Department of Family and Community Medicine, College of Medicine, King Abdulaziz Univerdity 3. Final Year Mbbs Student, King Abdul Aziz Medical College, Jeddah

$\square$ Corresponding author: Hassan B. Usman, hassanbinusman@hotmail.com

Disclosures can be found in Additional Information at the end of the article

\section{Abstract}

\section{Introduction}

Junk food (JF) consumption trend is increasing in all parts of the world. The transition in lifestyle and dietary habits is leading to many non-communicable diseases. The objectives of this study are twofold: (1) To examine the prevalence of junk food consumption and factors associated with consuming junk food among Saudi adults in Jeddah; and (2) to compare the trends of junk food consumption among males and females in Jeddah.

\section{Methodology}

This cross-sectional study was conducted in five different Primary Health Care centers (PHCCs) of Jeddah working under Ministry of Health. The subjects were men $(\mathrm{n}=146)$ and women $(\mathrm{n}=$ 254) aged 18-67 years visiting these centers. Structured validated close ended questionnaire was filled by all the participants. Data analysis was done using SPSS. Chi-square was applied to analyze the difference between male and female JF consumption and multivariate logistic regression analysis was done to examine the risk factors.

\section{Results}

Overall the JF consumption in subjects with mean age $33.69 \pm 12.29$ years was highly prevalent in both genders $(86.5 \%)$; $($ men $=85.6 \%$ and women $=87.4 \%)$. Controlling for some demographic and socioeconomic variables, increased junk food consumption was independently associated with education $(\mathrm{OR}=2.47,95 \% \mathrm{CI}: 1.088-5.605, \mathrm{p}=0.031)$, individuals who had limited time $(\mathrm{OR}=3.82$, 95\% CI: $1.690-8.642$, $\mathrm{p}<0.001)$, for the change of routine and taste $(\mathrm{OR}=7.64,95 \%$ CI: 3.145-18.563, p < 0.001 and $\mathrm{OR}=11.031$, 95\% CI: 4.219-28.843, p < 0.001, respectively).

Received 12/12/2017

Review began 12/16/2017 Review ended 12/23/2017 Published 12/31/2017

\section{(c) Copyright 2017}

Mandoura et al. This is an open access article distributed under the terms of the Creative Commons Attribution License CC-BY 3.0., which permits unrestricted use, distribution, and reproduction in any medium, provided the original author and source are credited.

\section{Conclusion}

The study findings provide evidence on the high prevalence of junk food consumption among Saudi adults. Junk food has influence in the dietary patterns of Saudi adults and this trend is likely to rise. This growing widespread use of junk food is of concern which may cause obesityrelated non-communicable diseases.

Categories: Public Health, Epidemiology/Public Health

Keywords: adults, junk food, prevalence, primary health care centres, restaurants 


\section{Introduction}

Junk food (JF) is defined as a food which is readily available, usually inexpensive, may or may not be nutritious [1]. Such food contains more calories, more salt, have a higher content of saturated fat and contains less iron, calcium and dietary fiber [2,3]. Common junk food includes fast food, carbonated drinks, chips, desserts, chocolates, etc. [4]. Adult's food choices are not consistent with the dietary guidelines, leading to many preventable diseases [5]. Over the past few decades, junk food consumption has increased worldwide [5]. Consuming large amounts of junk food is associated with a dramatic decrease in healthy food like milk, fruits and vegetables intake [6]. High income, rapid urbanization, free home deliveries, mouthwatering advertisements and international cuisines have contributed to a rising trend in increased junk food intake $[4,7]$.

Visible changes in the lifestyle patterns are noticed once the individual reaches his/her adolescence [8]. The tradition of family dinner is getting replaced by eating "on the run" [9]. Unfortunately, these modifications are usually not healthy, ranging from eating junk food in restaurants to lack of physical activity $[10,11]$. Based on some recent reports, more than onethird adults consume junk food two or even more times during a week [12]. Other reasons for these unhealthy habits include eating junk for pleasure, taste, laziness, friends company, independence and easy availability of these amenities [8-10]. These unhealthy habits have several adverse effects on health $[11,12]$.

Nutritious food plays an important role in the body development and prevention of diseases. Modern day deviation from organic and pure diet affects an individual's health [13]. Studies prove such food to cause obesity (central adiposity); a primary cause of heart diseases and other non-communicable diseases (NCDs) $[2,4,14]$. The burden of NCDs has become a major public health concern all over the world, attributed to the unhealthy life style which includes unhealthy dietary habits, physical inactivity and smoking $[5,8,9]$. Fortunately, NCDs are preventable [7]. A strong association lies between NCDs and lifestyle habits [7,9-11].

Increase in the junk food consumption is a global phenomenon having a prevalence of around $70 \%[13,14]$. It is considered as an emerging major public health challenge among all age groups and especially in young adults with a male predominance [12,14]. Schmidt, et al. [15] highlighted that the frequency of fast food consumption increases with increase in age (from adolescent to adults). Other studies highlighting reasons for increased consumption of junk food have given an insight to avoid them, but unfortunately measures taken are not as effective as they need to be $[4,6,14]$. In this modern era, it seems to have engulfed members of every age and race $[7,8,11]$.

Recent studies have shown that the trends in junk food consumption especially in the adolescents and young adults, as well as the number of fast food restaurants have significantly increased in Saudi Arabia also [8]. The dietary habits developed at a young age are important as these behaviors are likely to remain stable for the entire lifespan [14,15]. This is an important health concern especially in the urban areas. The purpose of this study is to assess the trends of junk food consumption and factors leading to its increased uptake in adults. Determining the factors for this increased JF consumption could be used as a guide for conducting interventions, aiming to help them adopt healthy eating behaviors.

\section{Materials And Methods}

A cross-sectional interview-based study with a duration of five months from 1st February 2017 to 1st July 2017 was conducted in the primary health care centers (PHCCs) in Jeddah, working under Ministry of Health. This study included Saudi adults (Male and female) above 18 years visiting different PHCCs. The sample size was calculated according to available/previous 
prevalence of junk food consumption among adults in Saudi Arabia (from study conducted in Riyadh [8]) using Epi Tools Sample size calculator. According to this study, the prevalence of those who eat fast food at least every week is $60 \%$. Using these figures, keeping the level of significance at $95 \%$ and desired precision at 0.5 the calculated sample size was 369 . Multi-stage sampling technique was adopted. The PHCCs were stratified according to administrative distribution of Jeddah city (North, South, West, East and Middle Sectors). One PHCC was selected from each sector randomly using lottery method. Systematic sampling of the participants was done according to the calculated sample size (80 individuals from each center).

Data was collected in a face to face interview using a valid descriptive questionnaire with slight modification which was obtained from the previous study conducted in Saudi Arabia [8]. Data analysis was done on SPSS version 22 (IBM SPSS Statistics for Windows, Version 22.0. Armonk, NY: IBM Corp). Chi-square was used to analyze categorical variables. Variables that were significantly associated with junk food consumption in the chi-square analyses were included as covariates in the multivariate regression models (using a backward stepwise [likelihood Ratio] method) to evaluate the predictors for increased JF consumption. In logistic regression individuals consuming JF were referent group, and were compared via odds ratio to individuals who did not claim to be eating JF or were not regular JF consumers. To generate the best fit model, 16 independent variables have been entered and a total of 15 steps have been run.

All Saudi adults aged 18 and above, coming to selected PHCCs whether having disease or attendants and willing to participate were included in this study. However, non-Saudi coming to the PHCCs and who were not falling in the age group mentioned earlier were excluded. Official permission was taken from Ministry of Health and Directorate of Health Affairs Jeddah Public Health Management for data collection (H-02-J-002-00762). Verbal consent was taken from the participants after explaining the aim of this study and confidentiality of data was ensured.

\section{Results}

The mean age of the study population was $33.69 \pm 12.29$ years. Of the 400 study participants, $36.5 \%(n=146)$ were males and $63.5 \%(n=254)$ were females. JF consumption was prevalent among all ages, both genders, belonging to different education level and occupational status (Table 1). Around $86.5 \%$ of the total sample reported consuming junk food (Table 1). 


\section{Cureus}

\begin{tabular}{|c|c|c|c|c|}
\hline \multicolumn{2}{|l|}{ Variable } & $\begin{array}{l}\text { Total } n=400 \\
(\%)\end{array}$ & $\begin{array}{l}\text { Individuals having junk } \\
\text { food }\end{array}$ & p-value \\
\hline \multirow{2}{*}{ Gender } & Male & $146(36.5)$ & $125(85.6)$ & \multirow{2}{*}{0.647} \\
\hline & Female & $254(63.5)$ & $222(87.4)$ & \\
\hline \multirow{2}{*}{ Educational status } & $\begin{array}{l}\text { Secondary school education or } \\
\text { lower }\end{array}$ & $125(31.3)$ & $100(80.0)$ & \multirow{2}{*}{0.007} \\
\hline & College education or higher & $275(68.8)$ & 247 (89.8) & \\
\hline \multirow{5}{*}{ Occupation } & Student & $94(24.0)$ & $92(95.8)$ & \multirow{5}{*}{$<0.001$} \\
\hline & Unemployed & $60(15)$ & $50(83.3)$ & \\
\hline & Employed & $151(37.8)$ & $136(90.1)$ & \\
\hline & House wife & $71(17.8)$ & $59(83.1)$ & \\
\hline & Retired & $22(5.5)$ & $10(45.5)$ & \\
\hline \multirow{4}{*}{ Marital status } & Single & $135(33.8)$ & $127(94.1)$ & \multirow{4}{*}{$<0.001$} \\
\hline & IMarried & $246(61.5)$ & $209(85.0)$ & \\
\hline & Divorced & $16(4.0)$ & $10(62.5)$ & \\
\hline & Widow & $3(0.75)$ & $1(33.3)$ & \\
\hline \multirow{3}{*}{$\begin{array}{l}\text { Living } \\
\text { arrangements }\end{array}$} & Living alone & $27(6.8)$ & $23(85.2)$ & \multirow{3}{*}{0.757} \\
\hline & Living with family & $369(92.3)$ & $321(87.0)$ & \\
\hline & Living with friends & $4(1.0)$ & $3(75.0)$ & \\
\hline
\end{tabular}

TABLE 1: Demographic and socioeconomic characteristics of study sample by junk food intake status.

A comparison of different forms of junk food preferences by males and females is given in Figure 1. Gender difference in the food preferences was less. Mostly burgers, pizzas, chicken broast were preferred food choices for both males and females. Major difference was noted in the consumption of hot dogs, shawarma and energy drinks, which were mostly liked by males however ice creams and chocolate bars, etc. were being utilized more by the females (Figure 1). 


\section{Cureus}

\section{JUNK FOOD CONSUMPTION PATTERN}

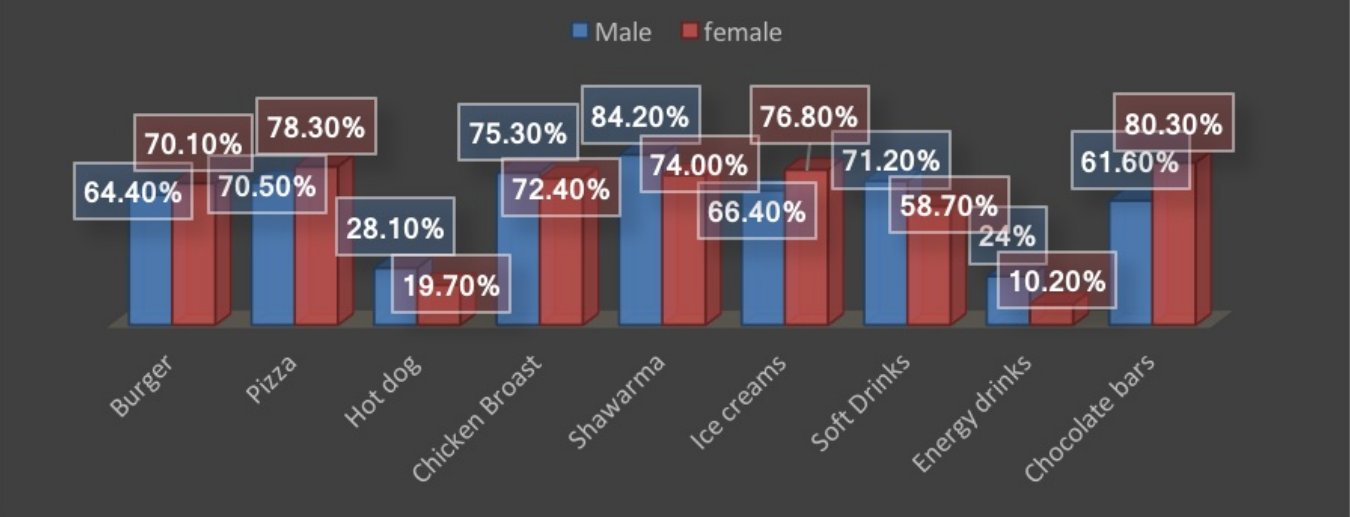

FIGURE 1: Gender differences in type of junk food.

Females mostly eat junk food once or twice a week. However, a significant difference $(\mathrm{p}=0.015)$ was noted in eating more than four to five times a week; males (17.8\%) eating JF more than females (7.9\%). Men prefer eating out over the weekends (38.4\%) as compared to females (26.4\%). Around 33.6\% males were in favor of eating out from a local restaurant as they want to encourage local products $(\mathrm{p}=0.029)$. Other gender differences are given in Table 2. Males usually prefer medium to large serving size (66.5\%) however females prefer small serving size (56.3\%) (Table 2). 


\section{Cureus}

\begin{tabular}{|c|c|c|c|c|}
\hline \multicolumn{2}{|l|}{ Variables } & $\begin{array}{l}\text { Male, } n=146 \\
(\%)\end{array}$ & Female, $\mathrm{n}=254(\%)$ & $\mathrm{p}$-value \\
\hline \multirow{4}{*}{ How often do you eat junk food } & Once or twice a week & $57(39.0)$ & $126(49.6)$ & \multirow{4}{*}{0.015} \\
\hline & 2-5 times/week & $52(35.6)$ & $92(36.2)$ & \\
\hline & More than 4-5 times/week & $26(17.8)$ & $20(7.9)$ & \\
\hline & Do not eat/not regular & $11(7.5)$ & $16(6.3)$ & \\
\hline \multirow{5}{*}{ When do you usually consume JF } & No specific time & $68(46.6)$ & $155(61.0)$ & \multirow{5}{*}{0.017} \\
\hline & Beginning of week & $5(3.4)$ & $2(0.8)$ & \\
\hline & Middle & $6(4.1)$ & $14(5.5)$ & \\
\hline & Weekend & $56(38.4)$ & $67(26.4)$ & \\
\hline & Do not eat/not regular & $11(7.5)$ & $16(6.3)$ & \\
\hline \multirow{4}{*}{ From where do you usually buy JF } & Local & $49(33.6)$ & $32(12.6)$ & \multirow{4}{*}{$<0.001$} \\
\hline & International & $20(13.7)$ & $56(22.0)$ & \\
\hline & Both & $66(45.2)$ & $150(59.1)$ & \\
\hline & Do not eat/not regular & $11(7.5)$ & $16(6.3)$ & \\
\hline \multirow{4}{*}{ Why do you prefer local places } & Cheap & $48(32.9)$ & $74(29.1)$ & \multirow{4}{*}{0.029} \\
\hline & Delicious & $57(39.0)$ & $134(52.8)$ & \\
\hline & $\begin{array}{l}\text { Encourage national } \\
\text { products }\end{array}$ & $30(20.5)$ & $30(11.8)$ & \\
\hline & Do not eat/not regular & $11(7.5)$ & $16(6.3)$ & \\
\hline \multirow{4}{*}{$\begin{array}{l}\text { Why do you prefer international } \\
\text { chains }\end{array}$} & Delicious & $94(64.4)$ & $173(68.1)$ & \multirow{4}{*}{0.866} \\
\hline & $\begin{array}{l}\text { Better service and } \\
\text { standards }\end{array}$ & $29(19.9)$ & $44(17.3)$ & \\
\hline & Original source & $12(8.2)$ & $21(8.3)$ & \\
\hline & Do not eat/not regular & $11(7.5)$ & $16(6.3)$ & \\
\hline
\end{tabular}

TABLE 2: Gender differences regarding the use of junk food restaurants $(n=400)$.

Bivariate analysis using chi-square shows an increased consumption of junk food depending on the emotional state. Increase in the junk food intake was noticed when the individuals were happy ( $\mathrm{p}=<0.001)$, angry or under stress $(\mathrm{p}=<0.001)$. Unavailability of ample time, inspired by taste along with change of routine for majority (both males and females) were few main reasons for preferring junk food (Figure 2). Convenience and easy availability while hanging out and socializing with friends and family were also identified as major contributors for an 


\section{Cureus}

increased junk food consumption especially among females (Figure 2).

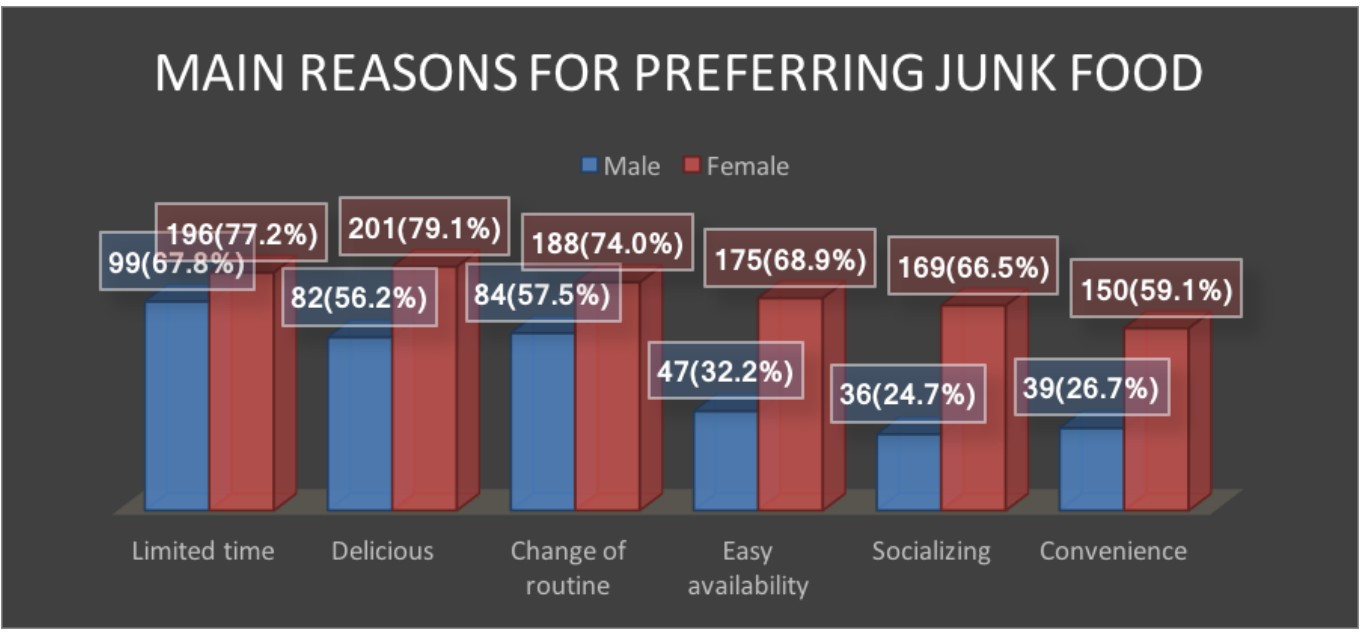

FIGURE 2: Main reasons for junk food preferences.

Multiple logistic regression fit model for identifying more junk food consumption included only four independent variables (education, unavailability of time, change of daily routine and for scrumptious food) after controlling for age and gender, which are all significant. Table 3 indicates that the risk of JF consumption was two times increased among participants who were educated ( $\mathrm{OR}=2.47,95 \% \mathrm{CI}: 0.178-0.919, \mathrm{p}=0.031$ ), and around four times in individuals who had limited time $(\mathrm{OR}=3.81,95 \% \mathrm{CI}: 0.116-0.592, \mathrm{p}=0.001)$. Other results of regression analysis for individuals who wanted to change the routine and those who considered JF more delicious are given in Table 3.

\begin{tabular}{|c|c|c|c|c|c|c|c|}
\hline \multirow{2}{*}{ Variables } & \multirow{2}{*}{ B } & \multirow{2}{*}{ SE } & \multirow{2}{*}{ Wald } & \multirow{2}{*}{ Sig } & \multirow{2}{*}{$\operatorname{Exp}(B)$} & \multicolumn{2}{|c|}{$95 \% \mathrm{Cl}$} \\
\hline & & & & & & Lower & Upper \\
\hline Education & -0.904 & 0.418 & 4.676 & 0.031 & 0.405 & 0.178 & 0.919 \\
\hline Limited time available & -1.341 & 0.416 & 10.372 & 0.001 & 0.262 & 0.116 & 0.592 \\
\hline Change of routine & -2.034 & 0.453 & 20.164 & $<0.001$ & 0.131 & 0.054 & 0.318 \\
\hline Delicious taste & -2.401 & 0.490 & 23.968 & $<0.001$ & 0.091 & 0.035 & 0.237 \\
\hline Constant & 4.403 & 0.454 & 93.967 & $<0.001$ & 81.729 & & \\
\hline
\end{tabular}

\section{TABLE 3: Multivariate regression analysis predicting factors for junk food consumption.}

B: Correlation coefficient; SE: Standard error; Wald: Wald Chi Square; Sig: Significant (p-value); Exp (B): Exponentiation B (Odds ratio); Cl: Confidence interval.

After adjusting for age and gender, variables (marital status, occupation, when angry, happy, under stress, delicious taste, attractive advertisements, easy availability with convenience, 
price and nutritional value) were excluded after logistic regression analysis (using a backward stepwise method).

\section{Discussion}

This study highlighted the high prevalence of JF consumption among Saudi adults. A dramatic lifestyle change is noticed in Saudi population over the last few decades [8]. This change is not only in the form of sedentary lifestyle but also in the dietary patterns. This energy dense and sugar-sweetened modern day dietary pattern is at the expense of nutrient dense food [16,17]. A number of studies are highlighting these increasing trends of junk food consumption worldwide $[12,15,17]$. The trend of eating outside the home is becoming a regular component not only of the Western world, but the studies conducted in the developing countries also show an increase in it $[7,16]$.

A study conducted in 2011 estimated that approximately 80\% of Michigan adults aged 18 to 54 years went to fast-food restaurants at least once per month and $28 \%$ consumed fast food regularly (i.e., $\geqslant 2 /$ week). The same study reported that fast food is consumed frequently in the United States and that prevalence of fast-food consumption has increased significantly in the past few decades [18]. Junk food consumption of more than two times per week (36\%) by our female study participants was much more than $25 \%$ reported by Al-Hazzaa, et al. [19]. However, fast food consumption frequency (77\%) of one to two times per week by our study participants was almost similar to study conducted in Riyadh where it was about 75\% [20]. A study conducted in the United Kingdom indicated 58\% adult residents using JF at least once a week [21]. Similarly, 28\% Australian population is consuming take away fast food meals at least twice a week [22]. Another study conducted in Brazilian students showed that around 70\% students eat JF four times or more per week [23]. A study conducted in 2010 in Riyadh on 127 adolescent Saudi girls (13-18 years) and 69 young adult Saudi girls (19-29 years) showed a vast majority of the participants (95.4\%) eating out in restaurants. It was consumed once per week by $52.8 \%$ of adolescent girls and $60.9 \%$ of young adult girls [8]. A regional study in Kuwait in 2011 reported that fast food intake among Arab adults is about 92\%. The weekly frequency intake of fast food was higher among men than women [24].

Different emotional factors also have an effect on the junk food consumption frequency. Studies show that fast food consumption increases when an individual is under stress. Similarly, it also increases when one is feeling positive and happy; the latter being a major factor for increased fast food consumption [16,17]. Similar findings were reported in our study participants too.

Burger and pizza was the most popular choice in the American college students [25]. Carbonated soft drinks have been reported to be the most frequently ordered beverage with food not only in America [25] but in other parts of Saudi Arabia also [19]. This current study findings replicate the findings of these two studies. Serving size of medium to large by men and small by the females was highlighted in our study. Almost similar findings were reported by Nora, et al. [8] and Driskell, et al. [25].

Although there was no specific time for consuming fast food, however, males (38.4\%) were utilizing weekend more than females (26.4\%). This could be due to the fact that men hanging out with friends over the weekend is common in our society. Our findings were not in accordance with the study conducted by Nora, et al. [8] where females mostly go out on weekends.

Study conducted in the USA [25] demonstrated limited available time as a main reason for preferring junk food; similar findings were revealed in our study too. This limited time is due to the modern day fast life style. Delicious taste is the second commonest reason for preferring junk food. Females mainly prefer JF because of its easy availability and convenience. Recent 
rapid mushrooming of outlets with free home delivery may be the possible reason. Similarly, a study conducted on Saudi young females showed delicious taste followed by convenience as the main reasons for increased junk food consumption [8].

Deliciousness of the local food was a common factor for attracting a lot of study subjects, similar to study findings of Nora, et al. [8]. Although the junk food consumption in both the genders was almost similar, but males prefer eating from a local brand more as compared to females. Reason identified for this preference was to encourage local brands. Females prefer international brands more because of its delicious taste and better services and standards. Brand names and attractive advertisements were not much an influence on our study participants as compared to Australian and American youth [26,27].

Regression analysis showed educated people going for more junk food. It may be because they are earning better than the less educated. People having routine home food the whole week want a change; therefore, they opt for junk food. Similar findings were noticed in studies conducted in other Saudi cities, Australia and the USA [8,19,26,27].

The main limitation of our study was not calculating body mass index (BMI) and not asking about their knowledge regarding harmful health effects of overconsumption of junk food products. Despite these limitations, the quantitative design gives a deep insight into factors influencing junk food consumption among Saudi adults.

\section{Conclusions}

The study findings provided evidence on the high prevalence of junk food consumption among Saudi adults. The focus of our findings included individual's preferences, consumption rates and identification of factors responsible for increased junk food utilization. In summary, junk food has influenced the dietary patterns of Saudi adults and this trend is likely to rise. This growing widespread use of junk food is of concern which may cause obesity-related NCDs.

To achieve a healthy life, JF consumption should be limited. To improve the dietary habits and food choices of Saudi population, community-based nutrition-related educational interventions should be conducted.

\section{Additional Information \\ Disclosures}

Human subjects: Consent was obtained by all participants in this study. Ministry of Health, Jeddah issued approval H-02-J-002-00762. Animal subjects: All authors have confirmed that this study did not involve animal subjects or tissue. Conflicts of interest: In compliance with the ICMJE uniform disclosure form, all authors declare the following: Payment/services info: All authors have declared that no financial support was received from any organization for the submitted work. Financial relationships: All authors have declared that they have no financial relationships at present or within the previous three years with any organizations that might have an interest in the submitted work. Other relationships: All authors have declared that there are no other relationships or activities that could appear to have influenced the submitted work.

\section{Acknowledgements}

Authors would like to acknowledge Rasha Muhammad Alharbi, Atheer Ambarak Al Gahtani, Maram Rasheed Alharbi, Ghaidaa Ali Alhazmi, Ghadeer Ali Alhazmi, Ahmed Ali Alzahrani, Shroog Abdulrehman Alghamdi, Maryam Mudhhi Alshehri, Salwa Mohammad Albalawi, Fahad 
Mohammed Mobark AlFaran for their help in data collection.

\section{References}

1. Seo HS, Lee SK, Nam S: Factors influencing fast food consumption behaviors of middleschool students in Seoul: an application of theory of planned behaviors. Nutr Res Pract. 2011, 5:169-178. 10.4162/nrp.2011.5.2.169

2. Vinay GJ, Sriram S, Kannabiran K, et al.: Student's perspective on junk foods: survey. Sudanese J Public Health. 2012, 7:21-25.

3. Horsu EN, Yeboah ST: Consumer perception and preference of fast food: a study of tertiary students in Ghana. Sci J Bus Manage. 2015, 3:43-49. 10.11648/j.sjbm.20150301.16

4. Phillips SM, Bandini LG, Naumova N, et al.: Energy-dense snack food intake in adolescence: longitudinal relationship to weight and fatness. Obes Res. 2004, 12:461-472. 10.1038/oby.2004.52

5. Bahadoran Z, Mirmiran P, Golzarand M, et al.: Fast food consumption in Iranian adults; dietary intake and cardiovascular risk factors: Tehran Lipid and Glucose Study. Arch Iran Med. 2012, 15:346-351. 012156/AIM.006

6. Laxer RE, Janssen I: The proportion of excessive fast-food consumption attributable to the neighborhood food environment among youth living within $1 \mathrm{~km}$ of their school. Appl Physiol Nutr Metab. 2014, 39:480-486. 10.1139/apnm-2013-0208. Epub 2013 Nov 18

7. Sajwani RA, Shoukat S, Raza R, et al.: Knowledge and practice of healthy lifestyle and dietary habits in medical and non-medical students of Karachi, Pakistan. J Pak Med Assoc. 2009, 59:650-655.

8. ALFaris NA, Al-Tamimi JZ, Al-Jobair MO, et al.: Trends of fast food consumption among adolescent and young adult Saudi girls living in Riyadh. Food Nutr Res. 2015, 59:26488. 10.3402/fnr.v59.26488

9. Jabs J, Devine CM: Time scarcity and food choices: an overview . Appetite. 2006, 47:196-204. 10.1016/j.appet.2006.02.014

10. Story M, Neumark-Sztainer D, French S: Individual and environmental influences on adolescent eating behaviors. J Am Diet Assoc. 2002, 102:40-51. 10.1016/S00028223(02)90421-9

11. Dixon HG, Scully ML, Wakefield MA, et al.: The effects of television advertisements for junk food versus nutritious food on children's food attitudes and preferences. Soc Sci Med. 2007, 65:1311-1323. 10.1016/j.socscimed.2007.05.011

12. Bauer KW, Larson NI, Nelson MC, et al.: Socio-environmental personal and behavioural predictors of fast-food intake among adolescents. Pub Health Nut. 2009, 12:1767-1774. $10.1017 /$ S1368980008004394

13. World Health Organization: Diet, Nutrition, and the Prevention of Chronic Diseases . World Health Organization, Geneva, Switzerland; 2003.

14. Rouhani MH, Mirseifinezhad M, Omrani N, et al.: Fast food consumption, quality of diet, and obesity among Isfahanian adolescent girls. J Obes. 2012, 2012:597924. 10.1155/2012/597924

15. Schmidt M, Affenito SG, Striegel-Moore R, et al.: Fast-food intake and diet quality in black and white girls: the National Heart, Lung, and Blood Institute Growth and Health Study. Arch Pediatr Adolesc Med. 2005, 159:626-631. 10.1001/archpedi.159.7.626

16. Nisar N, Qadri MH, Fatima K, et al.: Dietary habits and life style among the students of a private Medical University Karachi. J Pak Med Assoc. 2009, 59:98-101.

17. Mikolajczyk RT, El Ansari W, Maxwell AE: Food consumption frequency and perceived stress and depressive symptoms among students in three European countries. Nutr J. 2009, 8:31. 10.1186/1475-2891-8-31

18. Anderson B, Rafferty AP, Lyon-Callo S, et al.: Fast-food consumption and obesity among Michigan adults. Prev Chronic Dis. 2011, 8:A71.

19. Al-Hazzaa HM, Abahussain NA, Al-Sobayel HI, et al.: Physical activity sedentary behaviors and dietary habits among Saudi adolescents relative to age, gender and region. Int J Behav Nutr Phys Act. 2011, 8:140. 10.1186/1479-5868-8-140

20. Alfawaz HA: The relationship between fast food consumption and BMI among university female students. Pak J Nutr. 2012, 11:406-410. 10.3923/pjn.2012.406.410

21. Grunert KG, Wills JM, Fernández-Celemín L: Nutrition knowledge, and use and understanding of nutrition information on food labels among consumers in the UK. Appetite. 2010, 55:177- 


\section{Cureus}

189. 10.1016/j.appet.2010.05.045

22. Smith KJ, McNaughton SA, Gall SL, et al. : Takeaway food consumption and its associations with diet quality and abdominal obesity: a cross-sectional study of young adults. Int J Behav Nutr Phys Act. 2009, 6:29. 10.1186/1479-5868-6-29

23. Cimadon HM, Geremia R, Pellanda LC: Dietary habits and risk factors for atherosclerosis in students from Bento Gonçalves (state of Rio Grande do Sul). Arq Bras Cardiol. 2010, 95:166172. 10.1590/S0066-782X2010005000088

24. Musaiger AO: Consumption health attitudes and perception toward fast food among Arab consumers in Kuwait: gender differences. Glob J Health Sci. 2014, 6:136-143. 10.5539/gjhs.v6n6p136

25. Driskell JA, Meckna BR, Scales NE: Differences exist in the eating habits of university men and women at fast-food restaurants. Nutr Res. 2006, 26:524-530. 10.1016/j.nutres.2006.09.003

26. Robinson TN, Borzekowski DL, Matheson DM, et al.: Effects of fast food branding on young children's taste preferences. Arch Pediatr Adolesc Med. 2007, 161:792-797. 10.1001/archpedi.161.8.792

27. Mohammad T, Barker S, Kandampully J: Multicultural student perceptions of fast food restaurant brands: an Australian study. J Hospit Leisure Market. 2005, 12:93-117.

10.1300/J150v12n04_06 